\title{
Parsimonious powertrain modeling for environmental vehicle assessments: part 2-electric vehicles
}

\author{
Roland Geyer $^{1}$ (D) Donald E. Malen ${ }^{2}$ \\ Received: 30 September 2019 / Accepted: 31 May 2020 / Published online: 15 June 2020 \\ (C) The Author(s) 2020
}

\begin{abstract}
Purpose Environmental assessments of electric vehicles (EV) require scientifically sound and robust fuel consumption models. The purpose of this paper is to introduce a novel method and model for calculating energy demand of battery electric (BEV) and series plug-in hybrid electric (PHEV) vehicles.

Methods This paper presents an open-source simulation model for BEV and series PHEV powertrains. It is based on driving and powertrain physics, such as a net force approach to calculate force demand at the tire patch, and the use of motor maps to model motor efficiency. The modeling approach is well suited to include important EV powertrain aspects, such as regenerative braking and battery charging and discharging losses.

Results The presented method provides parsimonious open-source EV powertrain modeling to the environmental assessment community. It enables the calculation of vehicle energy demand (in $\mathrm{MJ} / 100 \mathrm{~km}$ ) and so-called energy reduction values (in $\mathrm{MJ} /$ $100 \mathrm{~km}$ and $100 \mathrm{~kg}$ vehicle mass reduction) that are specific to each EV configuration and design change.

Conclusions The presented EV powertrain model complements the ICV powertrain model introduced in part 1 of this paper series. It uses the same modeling methods as the ICV model, which gives it the same modeling advantages, and also facilitates environmental comparisons across powertrain types.
\end{abstract}

Keywords Automotive life cycle assessments $\cdot$ Vehicle mass reduction $\cdot$ Powertrain models $\cdot$ BEVs $\cdot$ PHEVs

\section{Introduction}

For the last century, virtually, all automotive vehicles shared their basic design: an internal combustion engine, powered by gasoline or diesel, and steel as the dominant structural material (Geyer 2016). At least since the 1960s, vehicles were identified as a source of large environmental impacts and subject to growing environmental criticism. The initial concerns were

Responsible editor: Wulf-Peter Schmidt

Electronic supplementary material The online version of this article (https://doi.org/10.1007/s11367-020-01775-z) contains supplementary material, which is available to authorized users.

Roland Geyer

geyer@bren.ucsb.edu

1 Bren School of Environmental Science and Management, University of California, Santa Barbara, CA 93106, USA

2 Integrative Systems and Design, College of Engineering, University of Michigan, Ann Arbor, MI 48109, USA about air quality and direct human health impacts, such as lead emissions and photochemical smog. A more recent focus of environmental criticism and policy are automotive greenhouse gas emissions. This has led to the consideration and adoption of alternative fuels and structural materials, such as bio-ethanol, bio-diesel, aluminum, and fiber-reinforced polymers. All of these environmentally motivated design changes require life cycle assessment (LCA) in order to determine whether environmental impact is shifted rather than reduced overall (Sullivan and Cobas-Flores 2001; MacLean and Lave 2003).

A frequent environmental tradeoff in vehicle design is the shifting of environmental burden between life cycle stages, i.e., product, use, and end of life. A pertinent example is vehicle mass reduction based on material substitution (Modaresi et al. 2014; Das et al. 2016; Serrenho et al. 2017; Palazzo and Geyer 2019; Kim and Wallington 2013a; Geyer 2008). The production of many light-weight materials is greenhouse-gasintensive. Using these light-weight materials therefore typically increase vehicle production impacts. It will also reduce vehicle mass, which in turn reduces fuel consumption during 
vehicle use. Quantifying the environmental trade-off is not trivial and has been subject to numerous studies. Among other things, these studies require robust and scientifically sound fuel consumption modeling, which is the subject of this two part paper series.

The first part of the series introduced an open-source powertrain simulation model for internal combustion vehicles (ICVs) (Geyer and Malen 2020). The paper detailed the physics-based modeling methods and discussed typical model results. This second part of the series introduces an equivalent open-source powertrain simulation model for battery electric vehicles (BEVs) and series plug-in hybrid electric vehicles (series-PHEVs). In a series hybrid design, the engine is only used to generate electricity for the motor. In a parallel design, the engine and the motor can provide torque directly to the axles (Mi et al. 2011; Erjavec 2013; Peng 2006).

EVs are not a novel invention and have been around since the early twentieth century (Geyer 2016). After some success, they had all but disappeared in the 1920s, with the exception of some niche applications like golf carts and the iconic British milk float. The renaissance of EVs began with General Motor's EV concept called Impact, which was introduced during the 1990 Los Angeles Motor Show and later evolved into the EV1. By early 2000, EV1 production had stopped, however, and General Motors started reclaiming the leased vehicles.

In the meantime, California had started its low emission vehicle (LEV) program designed to reduce air quality impacts from California's vehicle fleet. The program includes a socalled zero emission vehicle (ZEV) mandate, which contains sales requirements for cars with no tailpipe emissions of air criteria pollutants. While the ZEV mandate was changed many times, it was never dropped from the LEV program and thus created legislative incentives for the development of EVs, including BEVs and fuel cell vehicles (FCVs) (Bedsworth and Taylor 2007).

The commercialization and sub-sequent continuous improvement and cost reduction of lithium-ion battery technology enabled a new wave of BEVs, which started with the Tesla Roadster in 2008. Since then, many car companies have introduced BEVs or PHEVs with lithium-ion batteries and have publicly declared their commitment to electromobility. The EV share of the global vehicle fleet is expected to grow significantly in the future. The need for environmental assessments of EVs will therefore increase, and with it the need for robust energy consumption models for EVs.

Fuel consumption of ICVs, FC, is typically expressed volumetrically, in liters per $100 \mathrm{~km}$. The response of fuel consumption to vehicle mass reduction, $\Delta \mathrm{FC} / \Delta \mathrm{VM}$, is frequently expressed in liters per $100 \mathrm{~km}$ and $100 \mathrm{~kg}$ mass reduction and also known as fuel reduction value FRV (Koffler and RohdeBrandenburger 2010; Kim and Wallington 2013a, b, 2015). In this paper, we use more general expressions of the same concepts. They are called energy demand, ED, and energy reduction value, ERV, which have the units megajoules (MJ) per $100 \mathrm{~km}$ and MJ per $100 \mathrm{~km}$ and $100 \mathrm{~kg}$ mass reduction, respectively. FC and FRV are readily converted to ED and ERV by multiplying them with the energy density of the used fuel.

LCAs and other environmental assessments of vehicles frequently require not just robust energy demand values, but also defensible changes in energy demand due to changes in vehicle characteristics, such as mass reductions. Most of the literature on fuel or energy reduction values (FRVs or ERVs) focuses on ICVs and the justification of using various simplifications and approximations (Koffler and RohdeBrandenburger 2018). However, powertrain simulation tools for electric vehicles are available in the public domain. One example is the FASTSim model from the National Renewable Energy Lab (Brooker et al. 2015). FASTSim also uses approximations, such as a polynomial relationship between the power output and the conversion efficiency of the engine/motor, while the presented powertrain model uses engine and motor maps to allow for more complex behavior and avoid approximations. The model can be easily updated by adding additional maps to it. The approach is also well suited for modeling regenerative braking and the charging and discharging losses of the drive battery.

The development of the presented powertrain model is guided by four modeling principles: The first principle is to only rely on driving and powertrain physics and avoid approximations or engineering rules of thumb (Ross 1997; Heywood 1988; Waters 1972). The second principle is to have a completely transparent computational structure, so that model users know exactly how everything is calculated. The third principle is to make the model intuitive and easy to use for non-experts. The fourth and final principle is to strike a balance between model accuracy and complexity, a modeling approach sometimes called parsimonious.

\section{Methods and data}

This paper is the second part of a two part series. Part 1 introduced a power train model for internal combustion vehicles (ICVs); this paper introduces a power train model designed to simulate battery electric vehicles (BEVs) and series plug-in hybrid electric vehicles (series-PHEVs), in which the engine is only used to charge the battery. The presented powertrain model should thus not be used to model parallel hybrid designs, in which the engine can also directly provide torque to the axles.

The overall simulation approach is the same for both power train models, which facilitates fuel consumption comparisons between equivalently sized ICVs and EVs. Vehicle energy demand is given in MJ of electricity or fuel per $100 \mathrm{~km}$ and 
calculated by moving a vehicle through a so-called driving cycle, which specifies vehicle velocity $v(t)$ (in meters per second) as a function of time $t$, typically given in time increments of $1 \mathrm{~s} t_{i}$. Net tractive force demand $F_{T}$ at the vehicle's tire patch is calculated for each second. If $F_{\mathrm{T}}$ is positive, the model calculates how much electricity is required to provide it. If $F_{\mathrm{T}}$ is negative, the model determines how much electricity can be recovered and stored in the battery. The energy demand of the modeled electric vehicle is the sum over the electricity or fuel inputs or outputs for each second of the driving cycle, normalized to $100 \mathrm{~km}$. All model calculations are implemented in Excel. The modeled powertrain components and their arrangements are shown in Fig. 1.

\subsection{Force demand at tire patch and secondary loads}

The net tractive force demand $F_{\mathrm{T}}$ at a vehicle's tire patch does not depend on power train design or specifics. It is thus calculated in the same way for EVs than it is for ICVs. This section summarizes rather than repeats the more detailed description that can be found in Part 1 of the paper series. The basic tractive force equation is $F_{\mathrm{T}}\left(t_{i}\right)=F_{\mathrm{R}}\left(t_{i}\right)+F_{\mathrm{D}}\left(t_{i}\right)+F_{\mathrm{A}}\left(t_{i}\right)$, with rolling resistance force $F_{\mathrm{R}}\left(t_{i}\right)$, aerodynamic resistance force $F_{\mathrm{D}}\left(t_{i}\right)$, and force demand due to acceleration/ deceleration $F_{\mathrm{A}}\left(t_{i}\right) . F_{\mathrm{A}}\left(t_{i}\right)$ is the only term that can be negative, the other two are either positive or zero. $F_{\mathrm{A}}\left(t_{i}\right)$ is calculated as vehicle mass times change in velocity $\Delta v(t) / \Delta t . F_{\mathrm{R}}\left(t_{i}\right)$ is calculated as vehicle mass times acceleration of gravity times rolling resistance coefficient of the tire. $F_{\mathrm{D}}\left(t_{i}\right)$ is a quadratic function of vehicle speed $v(t)$ and a linear function of the density of the air and the frontal area of the vehicle. $F_{\mathrm{T}}>0$ means the vehicle requires power from the motor; $F_{\mathrm{T}}<0$ means that frictional or regenerative breaking is required.

A secondary load is a power demand that is generated within the vehicle. One secondary load comes from the rotational inertia of rotating vehicle components such as tires, wheels, and driveline components. It can be modeled as an increase in the translational inertia, i.e., the vehicle mass. The other secondary load is called spin loss and is a resistance force that increases linearly with vehicle speed $v(t)$. Spin loss is caused by viscous forces within the drivetrain and typically determined empirically, e.g., through so-called coast down tests.

Now that translational vehicle speed $v\left(t_{i}\right)$ (in meters per second) and total net force demand $F_{\mathrm{T}}\left(t_{i}\right)$ (in Newton) are known for each second $t_{i}$ of the selected driving cycle, they can be converted into their rotational equivalents, rotational tire speed $\Omega_{T}\left(t_{i}\right)$ (in rad per second), and axle torque demand $T_{\mathrm{T}}\left(t_{i}\right)$ (in Newton meter), according to the equations $T_{\mathrm{T}}=r$. $F_{\mathrm{T}}$ and $\Omega_{T}=v / r$, with $r$ being the rolling radius of the tire.

A useful intermediate result that will enable us to calculate overall power train efficiency is the total energy demand at the tire patch, which is calculated as $\mathrm{ED}_{\mathrm{T}}=\sum_{i} F_{\mathrm{T}}\left(t_{i}\right) \cdot v\left(t_{i}\right)$ for all $F_{\mathrm{T}}\left(t_{i}\right)>0$ and given in MJ per km or $100 \mathrm{~km}$.

\subsection{Torque demand at motor or generator shaft}

The next step is to model the drive train components between the tires and the motor or generator. For PHEVs and BEVs, this only consists of a differential and, possibly, a transmission (Chana et al. 1977). The model calculations follow the power train backwards, or from left to right in Fig. 1. The differential and transmission gears are defined by their gear ratios and their torque/energy conversion efficiencies, which are used to convert the required torque and rotational speed output (in $\mathrm{Nm}$ and $\mathrm{rad} / \mathrm{s}$ ) into the corresponding torque and rotational speed input (Genta and Morello 2009; Flamand et al. 1998). Required torque input into the differential is thus calculated as $T_{\mathrm{D}-\text { in }}=T_{\mathrm{T}} /\left(\eta_{\mathrm{D}} \cdot R_{\mathrm{D}}\right)$, with $\eta_{\mathrm{D}}$ being the energy/torque conversion efficiency, $R_{\mathrm{D}}$ being the gear ratio of the differential, and $T_{\mathrm{D}-\text { out }}=T_{\mathrm{T}}$. Speed input into the differential is calculated as $\Omega_{\mathrm{D}-\text { in }}=R_{\mathrm{D}} \cdot \Omega_{\mathrm{D}-\text { out }}=R_{\mathrm{D}} \cdot \Omega_{\mathrm{T}}$.

The function of a transmission is to change torque and speed requirements of the wheel to values that are feasible and efficient for the power train. Electric motors have a wide range of efficient torque and speed values, so multiple gears are not strictly necessary. The capability of the powertrain model to simulate a transmission is therefore currently not activated, which simplifies the simulation. For each time step $t_{i}$ the resulting brake torque is simply $T_{\mathrm{B}}\left(t_{i}\right)=T_{\mathrm{D}-\text { in }}\left(t_{i}\right)$, and the resulting motor or generator speed is $\Omega_{\mathrm{B}}\left(t_{i}\right)=\Omega_{\mathrm{D}-\text { in }}\left(t_{i}\right)$.

Fig. 1 Overview of the PHEV-

$\mathrm{BEV}$ powertrain model

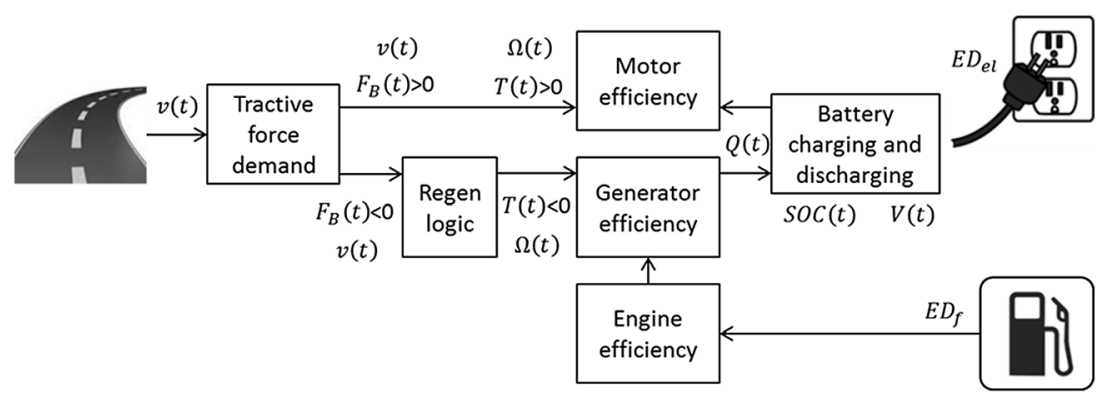




\subsection{Motor electricity demand}

If $T_{\mathrm{B}}\left(t_{i}\right)>0$, the next step of the powertrain model is to convert the torque demand at the motor shaft into electricity demand. Motor efficiency is a complex function of motor torque and speed, i.e., $\eta_{\text {motor }}\left(T_{B}, \Omega_{B}\right)$. The relationship has been determined empirically, through motor tests, and the resulting data is stored and visualized in so-called motor maps (UQM (n.d.)). The energy conversion efficiency of the motor used in this powertrain model ranges from 62 to $97 \%$.

For each time step $t_{i}$, the powertrain model looks up the motor efficiency that matches the required brake torque and engine speed. Most of the motor map is stored as a data table with $50 \mathrm{Nm}$ torque and $250 \mathrm{rpm}$ speed intervals. To increase model precision, linear interpolation is used to calculate the efficiency of each motor operating point.

Once the conversion efficiency of the motor at time $t_{i}$ is known, motor electricity demand at time $t_{i}$ is calculated as $\mathrm{ED}_{\mathrm{m}}\left(t_{i}\right)=\Omega_{\mathrm{B}}\left(t_{i}\right) \cdot T_{\mathrm{B}}\left(t_{i}\right) / \eta_{\text {motor }}\left(t_{i}\right)$. The electric energy demand for the specified vehicle and driving cycle is calculated as $\mathrm{ED}_{\mathrm{m}}=\sum_{i} \mathrm{ED}_{\mathrm{m}}\left(t_{i}\right) /(0.01 \cdot \mathrm{LDC})$ and given in $\mathrm{MJ} / 100 \mathrm{~km}$. LDC is the length of the driving cycle in kilometers and calculated as $\mathrm{LDC}=\sum_{i} v\left(t_{i}\right) / 1000$. Motor energy demand $\mathrm{ED}_{\mathrm{m}}$ excludes regenerative braking and battery charging/ discharging losses.

\subsection{Regenerative braking}

If $T_{\mathrm{B}}\left(t_{i}\right)<0$, the next step of the powertrain model is to simulate deceleration. Vehicle braking is, in general, shared by friction braking and regenerative braking (PDM (n.d.)). In this simplified model, the split between the two types of braking is determined by the following two conditions.

Condition 1: The braking torque provided by the generator must be less than or equal the generator's capacity, $T_{\text {Max }- \text { Gen. }}$ An example is shown in Fig. 2.

Condition 2: For low speeds, braking is done solely by friction braking, for high speeds entirely by regenerative braking. The transition zone between the two regimes is implemented with a function that uses a so-called speed factor, $\mathrm{SF}=T_{\mathrm{Reg}-\mathrm{B}} / T_{\mathrm{B}}$ (see Fig. 3) (Brooker et al. 2013).

For a given brake torque demand $T_{\mathrm{B}}$, the regenerative braking torque, $T_{\mathrm{Reg}-\mathrm{B}}$, is calculated as $T_{\mathrm{Reg}-\mathrm{B}}=\operatorname{Min}\left[-\mathrm{SF} \cdot T_{\mathrm{B}}\right.$, $\left.-\mathrm{SF} \cdot T_{\mathrm{Max}-\mathrm{Gen}}\right]$.

The product of $T_{\mathrm{Reg}-\mathrm{B}}$ and generator rotation speed are the mechanical power at the generator input shaft. Multiplying this mechanical power with the generator efficiency yields the electric power available for battery charging. Generator efficiency is a complex function of generator torque and speed, $\eta_{\text {gen }}\left(T_{\text {Reg-B }}, \Omega_{\mathrm{B}}\right)$. The relationship has been

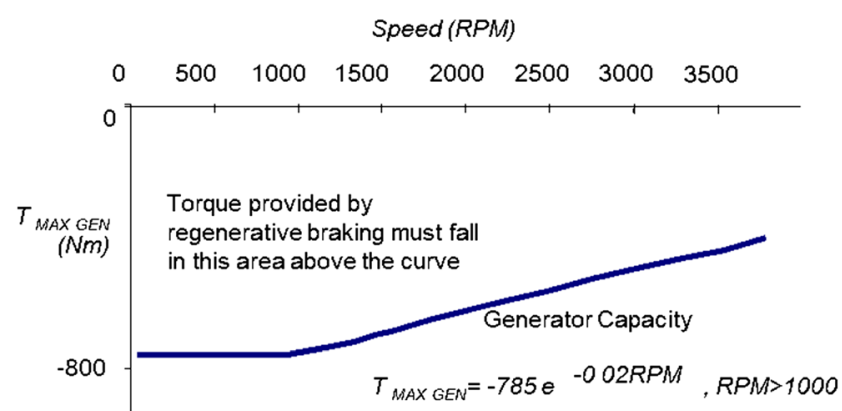

Fig. 2 Condition 1 for regenerative braking

determined empirically, and the resulting data is stored and visualized in a generator map. The energy conversion efficiency of the generator used in this powertrain model ranges from 25 to $95 \%$.

Once the conversion efficiency of the generator at time $t_{i}$ is known, generator electricity generation at time $t_{i}$ is calculated as $E_{\text {regen }}\left(t_{i}\right)=\Omega_{\mathrm{B}}\left(t_{i}\right) \cdot T_{\text {Reg }-\mathrm{B}}\left(t_{i}\right) \cdot \eta_{\text {motor }}\left(t_{i}\right)$. For the specified vehicle and driving cycle, the total amount of electricity generated due to regenerative braking is calculated as $E_{\text {regen }}=\sum_{i} E_{\text {regen }}\left(t_{i}\right) /(0.01 \cdot \mathrm{LDC})$ and given in $\mathrm{MJ} / 100 \mathrm{~km}$. LDC is the length of the driving cycle in kilometers and calculated as LDC $=\sum_{i} v\left(t_{i}\right) / 1000$. Recovered electric energy $E_{\text {regen }}$ excludes battery charging/discharging losses.

\subsection{Battery discharging and charging}

Battery charging or discharging is the conversion of electrical energy into chemical energy and back into electricity. Both conversions are not $100 \%$ efficient, and the $\mathrm{BEV} /$ seriesPHEV powertrain model thus needs to quantify the charging and discharging losses (USABC and DOE 1996).

Like all other powertrain processes, charging and discharging is simulated in $1 \mathrm{~s}$ increments. Energy losses during discharging are modeled through a drop in terminal voltage. Energy losses during charging are modeled through overpotentials at the battery terminal. Voltage drops and overpotentials are assumed to depend only on the state of charge (SOC) and power in-or output (PNGV 2001; Nelson et al. 2013a, b; Amirault et al. 2009). Voltage drops are taken from

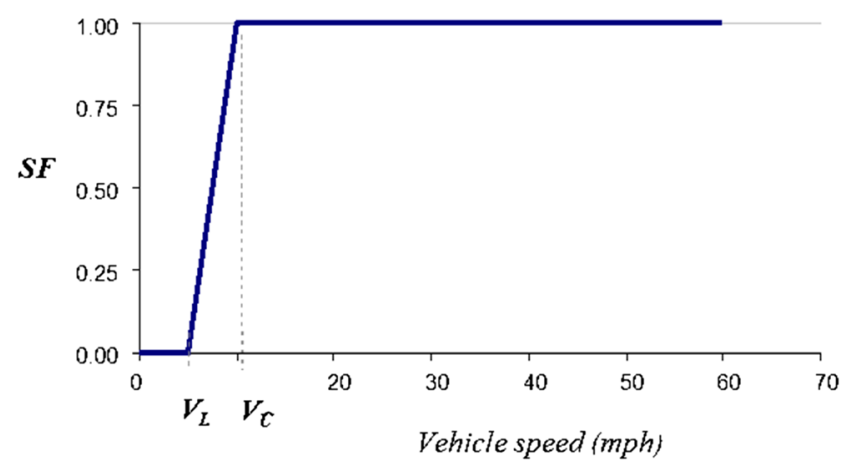

Fig. 3 Condition 2 for regenerative braking 
discharge curves of existing lithium-ion cells (A123 Systems 2012). Over-potentials are assumed to be symmetrical to voltage drops under equal power and SOC.

The calculation process is as follows:

1. Power demand from or supply to the battery during second $i$ is $P_{i}=\mathrm{ED}_{\mathrm{m}}\left(t_{i}\right)+E_{\text {regen }}\left(t_{i}\right)$.

2. $V_{\mathrm{i}}=f\left(P_{i}, \mathrm{SOC}_{i}\right)$ use electric power demand/supply $P_{i}$ during second $i$ and $\mathrm{SOC}_{\mathrm{i}}$ at beginning of second $i$ to look up voltage drop/over potential during second $i$ : $\Delta V_{i}=f\left(P_{i}, \mathrm{SOC}_{i}\right)$

3. Calculate the terminal voltage as $V_{i}=V_{\text {nominal }}-\operatorname{sign}\left(P_{i}\right)$ - $\Delta V_{i}\left(P_{i}, \mathrm{SOC}_{i}\right)$.

4. $A_{\mathrm{i}}=P_{\mathrm{i}} / V_{\mathrm{i}}$ calculate resulting current during second $i$ as power/voltage: $A_{i}=P_{i} / V_{i}$

5. $\Delta Q_{\mathrm{i}}=\frac{A_{\mathrm{i}}}{3600 \mathrm{sec}}$ calculate charge (in Ah) removed from or added to battery during second $i$ as current (in A) divided by $3600: \Delta Q_{i}=\frac{A_{i}}{3600 \mathrm{sec}}$.

6. $Q_{i+1}=Q_{i}-\Delta Q_{i}$ calculate new battery charge (in Ah) at begin of second $i+1$ as $Q_{i+1}=Q_{i}-\Delta Q_{i}$.

7. $\mathrm{SOC}_{i+1}=\frac{Q_{i+1}}{Q_{0}}$ calculate state of charge at beginning of second $i+1$ : $\mathrm{SOC}_{i+1}=\frac{Q_{i+1}}{Q_{0}}$

8. If $\mathrm{SOC}_{i+1}<\mathrm{DOD}$ then set $\mathrm{SOC}_{i+1}$ back to initial state of charge $\mathrm{SOC}_{0}$. This simulates a full stationary recharge of the battery from an electrical outlet.

9. Repeat for every second of the driving cycle.

10. At the end of the driving cycle, bring $\mathrm{SOC}$ from $\mathrm{SOC}_{\text {end }}$ back to $\mathrm{SOC}_{0}$ through one final stationary recharging of the battery.

The net amount of charge removed from the battery during the driving cycle is $\Delta Q_{\text {total }}=\sum_{i=1}^{\mathrm{end}} \Delta Q_{i}$. The total amount of energy lost during all stationary charging, $\mathrm{SCL}$, is calculated as

$$
\begin{aligned}
\mathrm{SCL}= & n \cdot \frac{\Delta V\left(P_{\min }, S O C_{0}\right)+\Delta V\left(P_{\min }, 1-\mathrm{DOD}\right)}{2} \cdot \frac{\left(\mathrm{SOC}_{0}-1+\mathrm{DOD}\right) \Delta Q_{\text {batt }}}{1,000} \\
& +\frac{\Delta V\left(P_{\min }, S O C_{0}\right)+\Delta V\left(P_{\min }, S O C_{\text {end }}\right)}{2} \cdot \frac{\Delta Q_{\text {total }}}{1,000}
\end{aligned}
$$

$n$ denotes the number of times the battery has to be fully recharged to complete the driving cycle. The total amount of electricity withdrawn from the plug is calculated as $E D_{e l}=\left(\frac{V_{\text {nominal }} \cdot \Delta Q_{\text {total }}}{1,000}+S C L\right) /(0.01 \cdot \mathrm{LDC}) . \mathrm{LDC}$ is the length of the driving cycle in kilometers and calculated as $\mathrm{LDC}=\sum_{i} v\left(t_{i}\right) / 1,000 . \mathrm{ED}_{e l}$ is the total energy demand, including battery discharging and charging losses, in charge depleting mode.

Driving in charge sustaining mode assumes that the onboard engine and generator are used to provide all charge removed from the battery $\Delta Q_{\text {total }}$, which means that no plug electricity is used and $\mathrm{SOC}_{\text {end }}=\mathrm{SOC}_{0}$. The total gasoline energy demand in charge sustaining mode is calculated as

$\mathrm{ED}_{f}=\frac{V_{\text {nominal }} \cdot \Delta Q_{\text {total }}}{1,000 \cdot \eta_{\text {generator }} \cdot \eta_{\text {gears }} \cdot \eta_{\text {engine }} \cdot 0.01 \cdot \mathrm{LDC}}$

$\eta$ denotes the efficiencies of generator, gear train, and engine (operated at maximum efficiency).

\subsection{Vehicle performance and motor resizing}

The EV powertrain model lets the user simulate changing the size of the vehicle's motor. The default motor map in the powertrain model is for a motor with a maximum torque of $650 \mathrm{~N}$ meter and a maximum power of $152 \mathrm{~kW}$. A larger or smaller motor can be simulated by taking the motor map and scaling the torque axis by a constant factor while leaving everything else the same (Anderson 2003). The user can choose the torque scaling factor $T_{\text {resized }} / T_{\text {base }}$ on the data input worksheet.

Motor resizing can be used to compare the electricity demand of two EVs with different vehicle masses but equal acceleration performance. If the mass of a vehicle is reduced, its acceleration performance will increase, all other things being equal. To calculate the electricity demand of a massreduced vehicle with the same acceleration performance as the baseline vehicle, the linear torque scaling factor can be adjusted as follows:

Enter all input data for the baseline vehicle and note the calculated 0-60 mph acceleration time. Reduce vehicle mass input data, the calculated 0-60 mph time will decrease as a result. Use the Excel goal seek function to set the 0-60 mph time back to the baseline value by changing the torque scaling factor, i.e., simulating a downsizing of the engine. The result is a mass-reduced vehicle with the same $0-60 \mathrm{mph}$ acceleration as the baseline vehicle.

The powertrain model calculates acceleration performance by calculating the time intervals it takes to accelerate the vehicle by $1 \mathrm{mph}$ increments. For each speed increment, $x$ $\mathrm{mph} \rightarrow x+1 \mathrm{mph}$, the model selects the maximum available torque, converts it into force at the tire patch, and uses the net force demand equation to calculate the time it takes to increase vehicle speed by one mile. The time it takes to accelerate from 0 to $60 \mathrm{mph}$ is simply the sum of the 60 time increments.

\section{Results and discussion}

The BEV/series-PHEV powertrain model has 25 input parameters, which enables many different analyses. This results section will focus on the impact of key vehicle characteristics on vehicle energy demand for different driving cycles and 0$60 \mathrm{mph}$ acceleration times. Those vehicle characteristics are 
vehicle mass $M$, frontal area $A_{\mathrm{F}}$, aerodynamic drag coefficient $c_{D}$, and rolling resistance coefficient $f_{R}$.

\subsection{Energy demand and key vehicle characteristics}

Figure 2 depicts vehicle energy demand as a function of vehicle mass $M$, frontal area $A_{F}$, and rolling resistance coefficient $f_{R}$. It does this for two driving cycles, NEDC, a so-called modal driving cycle, and Hyzem, an example of transient driving cycles, which involve more speed variation and are thus more representative of on-road driving. All three vehicle characteristics are varied by $\pm 10 \%, \pm 20 \%, \pm 30 \%$, and \pm $40 \%$ around baseline values typical for a compact BEV. The motor size was not adjusted for constant acceleration performance.

The response of energy demand to all three vehicle characteristics is essentially linear. All three characteristics enter the equation for net force at the tire patch $F_{T}\left(t_{i}\right)$ in a linear fashion. The aerodynamic drag coefficient $c_{D}$ enters the net force equation in the same way as frontal area $A_{F}$ and is therefore omitted in the analysis. That the relationships are not exactly linear is due to the fact that changing vehicle characteristics has a small impact on the selected set of motor operating points, which, in turn, determines the overall motor efficiency. The ratio $\mathrm{ED}_{\mathrm{T}} / \mathrm{ED}$ denotes the overall powertrain efficiency $\eta$ for a given vehicle and driving cycle. In the simulations shown in Fig. $4, \eta$ changes slightly as $M, A_{\mathrm{F}}$, and $f_{\mathrm{R}}$ varies. This means that the overall powertrain efficiency (calculated over the entire driving cycle) depends on the driving cycle and the entire vehicle configuration, and not just the motor alone.

Hyzem generates a consistently higher energy demand than NEDC due to higher speeds and more acceleration events. The energy demand in Hyzem is most sensitive to frontal area, while the energy demand in NEDC is most sensitive to vehicle mass. Both are least sensitive to the rolling resistance coefficient. Most and least sensitive is defined here in terms of equal percentage variations of the vehicle characteristics. It should be noted that the same motor map was used for all simulations in Fig. 4, and thus some of the underlying vehicle configurations may yield somewhat unrealistic car designs. Compared to the results for ICVs, shown in Part 1 of this paper series, energy demand of BEVs or series-PHEVs in charge depleting mode is considerably less sensitive to changes in $M, A_{\mathrm{F}}$, and $f_{\mathrm{R}}$, in particular to changes in vehicle mass.

\subsection{Impact of vehicle mass on energy demand and acceleration time}

For many environmental vehicle assessments, the impact of vehicle mass on energy demand is of particular interest. Figure 3 shows energy demand for five different driving cycles and 0-60 mph acceleration times for a typical compact electric vehicle configuration $\left(A_{\mathrm{F}}=2.4 \mathrm{~m}^{2}, r_{\text {tire }}=0.308 \mathrm{~m}\right.$, $\left.f_{\mathrm{R}}=0.0085, c_{\mathrm{D}}=0.31, P_{\max }=150 \mathrm{~kW}\right)$. Again, the functional relationship between fuel consumption and vehicle mass is almost linear. The same is true for the relationship between 0 and $60 \mathrm{mph}$ acceleration and vehicle mass. It can be seen that different driving cycles generate varying absolute levels of energy demand, with UDDS generating the lowest and Hyzem the highest. The energy demand of electric powertrains is less sensitive to vehicle mass and driving cycle than that of ICVs, which is illustrated by the small and similar gradients in Fig. 5.

\subsection{Change of energy demand due to change in vehicle mass}

The development of the presented powertrain model was motivated by the long-standing controversy about the best way to quantify changes in vehicle energy demand due to vehicle mass reduction, e.g., through the use of light-weight materials. The next section will therefore take an even closer look at the response of energy demand to vehicle mass reduction.

Table 1 shows the energy reduction value ERV in megajoules per $100 \mathrm{~km}$ driven and $100 \mathrm{~kg}$ mass reduction.
Fig. 4 Energy demand in charge depleting mode, $\mathrm{ED}_{\mathrm{el}}$, as a function of vehicle mass $M$ $(100 \%=1500 \mathrm{~kg})$, tire rolling resistance coefficient $f_{R}$ $(100 \%=0.0085)$, and frontal area $A_{F}\left(100 \%=2.4 \mathrm{~m}^{2}\right)$

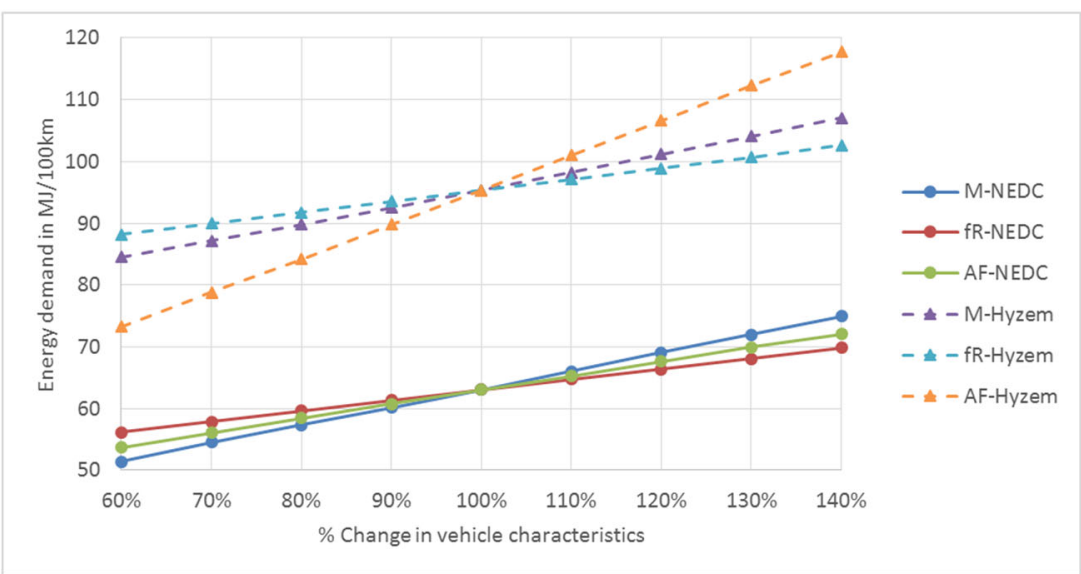


Fig. 5 0-60 mph acceleration time and energy demand $\mathrm{ED}_{\mathrm{el}}$ as a function of vehicle mass

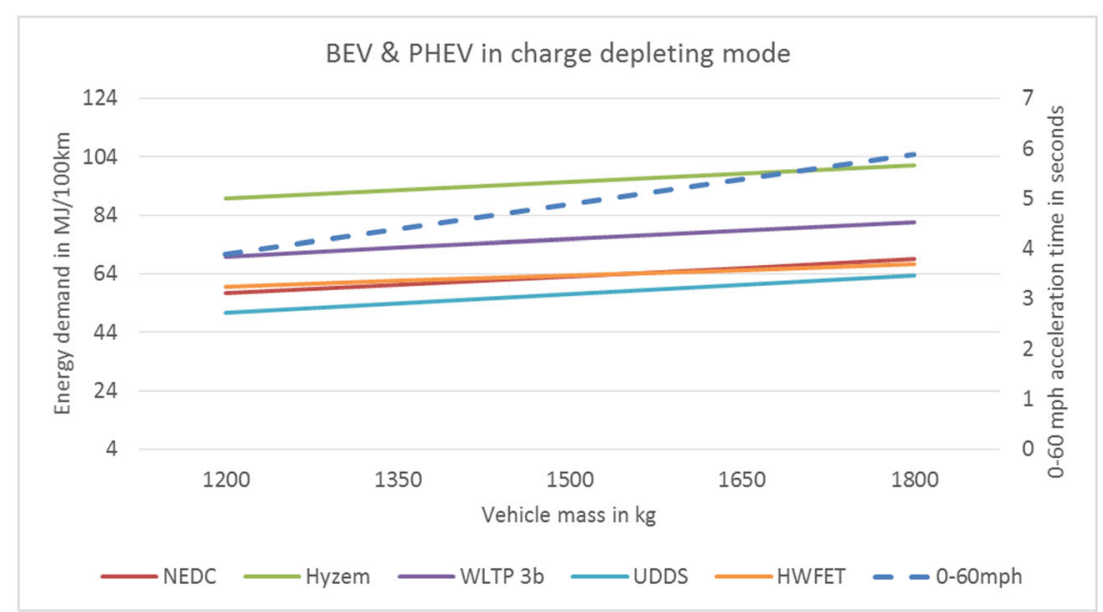

In this analysis, UDDS and HWFET are combined to yield the US combined driving cycle. Vehicle mass reduction can be considered and modeled as a stand-alone design change or combined with an adjustment of the powertrain. A frequently considered powertrain adjustment is the downsizing of the motor in order to obtain equal acceleration between original and mass-reduced vehicle. Table 1 therefore shows $E R V s$ for each driving cycle with and without motor resizing, which is done as described in Section 2.6. The table also shows ERVs for charge-depleting and charge-sustaining driving modes. The latter only applies to series-PHEVs. Vehicle parameters have been chosen in order to represent a compact and a midsize electric vehicle. A few basic vehicle characteristics are also shown in Table 1.

Table 1 Change in vehicle energy demand ED due to mass reduction with and without motor resizing (all values are in $\mathrm{MJ} / 100 \mathrm{~kg} 100 \mathrm{~km}$ )

\begin{tabular}{lcccc}
\hline & \multicolumn{2}{c}{ Vehicle A } & \multicolumn{2}{c}{ Vehicle B } \\
Baseline mass $(\mathrm{kg})$ & \multicolumn{2}{c}{1300} & 1700 \\
Frontal area $\left(\mathrm{m}^{2}\right)$ & \multicolumn{2}{c}{2.2} & 2.4 \\
Drag coefficient & \multicolumn{3}{c}{0.25} & 0.3 \\
Max. motor power $(\mathrm{kW})$ & \multicolumn{3}{c}{100} & \multicolumn{2}{c}{250} \\
All-electric range $(\mathrm{km})$ & \multicolumn{3}{c}{190} & 250 \\
Driving mode: charge & Depleting & Sustaining & Depleting & Sustaining \\
& \multicolumn{4}{c}{ Without motor resizing } \\
Hyzem & 1.88 & 5.78 & 2.03 & 6.24 \\
NEDC & 1.94 & 5.97 & 2.03 & 6.28 \\
US combined & 1.69 & 5.20 & 1.72 & 5.33 \\
WLTP 3b & 1.82 & 5.58 & 1.87 & 5.76 \\
& \multicolumn{4}{c}{ With motor resizing } \\
Hyzem & 2.78 & 8.54 & 3.01 & 9.25 \\
NEDC & 2.57 & 7.88 & 2.67 & 8.27 \\
US combined & 2.40 & 7.40 & 2.48 & 7.63 \\
WLTP 3b & 2.55 & 7.84 & 2.68 & 8.24 \\
\hline
\end{tabular}

The table shows results from two simulations rather than a comprehensive analysis of the powertrain model. Nevertheless, some patterns are noteworthy and consistent with theory. ERVs are smaller for more efficient powertrains, such as pure electric ones. ERVs without motor resizing are consistently smaller than those with motor resizing. The ERVs of the series-PHEV in charge-sustaining mode are similar to those of gasoline-powered ICVs and about 3 times larger than the ERVs of BEVs or series-PHEVs in charge-depleting mode. The ERVs for different driving cycles are very similar for BEVs or series-PHEVs in charge-depleting mode and show a slightly larger spread for series-PHEVs in charge sustaining mode. ERVs moderately increase from the smaller to the larger modeled vehicle.

As mentioned in Section 3.1, vehicle mass reduction not only impacts energy demand at the tire patch $\mathrm{ED}_{\mathrm{T}}$, but also the overall powertrain efficiency $\eta=\mathrm{ED}_{\mathrm{T}} / \mathrm{ED}$. ERVs conflate these two effects, and it is thus useful to conduct decomposition analysis.

A useful way to decompose the fuel reduction value $F R V$ is to separate the change in energy demand at the tire patch $\mathrm{ED}_{\mathrm{T}}$ from the change in power train efficiency $\eta=\mathrm{ED}_{\mathrm{T}} / \mathrm{ED}$ according to the following identity:

$$
\begin{aligned}
\mathrm{ERV} & =\mathrm{ED}_{1}-\mathrm{ED}_{2}=\mathrm{ED}_{T 1} \cdot \frac{1}{\eta_{1}}-\mathrm{ED}_{T 2} \cdot \frac{1}{\eta_{2}} \\
& =\left(\mathrm{ED}_{\mathrm{T} 1}-\mathrm{ED}_{\mathrm{T} 2}\right) \frac{1}{\eta_{1}}+\mathrm{ED}_{\mathrm{T} 2}\left(\frac{1}{\eta_{1}}-\frac{1}{\eta_{2}}\right)
\end{aligned}
$$

The equation shows ERV as the sum of the change in energy demand at the tire patch $\mathrm{ED}_{\mathrm{T}}$ at fixed power train efficiency and the change in power train efficiency at fixed energy demand at the tire patch. Subscript 1 denotes the vehicle design before mass reduction, while 2 stands for the vehicle after mass reduction.

Table 2 shows the decomposition of the ERVs from Table 1. It can be seen that vehicle mass reduction reduces the energy 
demand at the tire patch, but also changes the powertrain efficiency. In the examples shown in the table, mass reduction consistently reduces powertrain efficiency $\left(\eta_{1}>\eta_{2}\right)$. Mass reduction without motor resizing yields small changes in powertrain efficiency, $\left|\left(\eta_{1}-\eta_{2}\right) / \eta_{1}\right|$, ranging from 1.0 to $2.1 \%$. Efficiency changes due to mass reduction with motor resizing are minimal, ranging from 0 to $0.4 \%$. Without motor resizing, the effect of the changes in powertrain efficiency, $\mathrm{ED}_{\mathrm{T} 2}\left(\frac{1}{\eta_{1}}-\frac{1}{\eta_{2}}\right)$, is between 26 and $36 \%$ of the effect of the changes in $\mathrm{ED}_{\mathrm{T}},\left(\mathrm{ED}_{\mathrm{T} 1}-\mathrm{ED}_{\mathrm{T} 2}\right) \frac{1}{\eta_{1}}$. With motor resizing, the range is 1 to $7 \%$. Table 2 is also a reminder that the difference between ERVs with and without motor resizing (all other things being equal) are entirely due to a change in power train efficiency, since engine resizing has no impact on the energy demand at the tire patch $E D_{T}$.

\subsection{Comparing energy demand between BEVs and ICVs}

Part 1 of this paper series introduced the powertrain simulation model for ICVs. This second part introduces the powertrain simulation model for BEVs and series-PHEVs. Both models are based on the same methodology, which enables comparisons of driving energy demand and changes in driving energy demand across powertrain types. Any such comparisons require that equivalent vehicles with different powertrains are defined, which is not trivial and a frequent source of controversy (Samaras and Meisterling 2008; Hawkins et al. 2012). This section is meant to illustrate the comparative use of the two powertrain models with two examples, rather than present definitive comparisons. While it may be reasonable to choose identical vehicle specifications for many input parameters, e.g., for frontal area $A_{F}$, tire rolling radius $r_{\text {tire }}$, rolling resistance coefficient $f_{R}$, drag coefficient $c_{D}$, and engine/motor power $P_{\max }$, this is not true for all inputs. The most important input parameter is probably vehicle mass $M$. A BEV should be expected to be significantly heavier than an equivalent ICV due to the mass of the drive battery. Battery mass is a function of its electric storage capacity, which, in turn, determines the range of the vehicle. The question whether cars require equal single-fill ranges to be equivalent is firmly outside of the scope of this paper, so suffice it to say that the users of the powertrain models are at liberty to perform any comparisons they are interested in. Table 3 shows two examples of the type of
Table 2 Decomposing ERVs into change in $\mathrm{ED}_{\mathrm{T}}$ and change in powertrain efficiency $\eta$

\begin{tabular}{|c|c|c|c|}
\hline & \multirow[t]{2}{*}{$\left(\mathrm{ED}_{\mathrm{T} 1}-\mathrm{ED}_{\mathrm{T} 2}\right) \frac{1}{\eta_{1}}$} & \multicolumn{2}{|l|}{$\mathrm{ED}_{\mathrm{T} 2}\left(\frac{1}{\eta_{1}}-\frac{1}{\eta_{2}}\right)$} \\
\hline & & No engine resizing & $\begin{array}{l}\text { Engine } \\
\text { resizing }\end{array}$ \\
\hline \multicolumn{4}{|c|}{ Vehicle A in charge depleting mode } \\
\hline Hyzem & 2.92 & -1.04 & -0.14 \\
\hline NEDC & 2.66 & -0.72 & -0.10 \\
\hline $\begin{array}{l}\text { US } \\
\text { Combine }\end{array}$ & 2.49 & -0.81 & -0.09 \\
\hline WLTP $3 b$ & 2.73 & -0.92 & -0.18 \\
\hline \multicolumn{4}{|c|}{ Vehicle A in charge sustaining mode } \\
\hline Hyzem & 8.97 & -3.19 & -0.43 \\
\hline NEDC & 8.20 & -2.22 & -0.32 \\
\hline $\begin{array}{l}\text { US } \\
\text { Combine }\end{array}$ & 7.68 & -2.48 & -0.28 \\
\hline WLTP $3 b$ & 8.42 & -2.84 & -0.58 \\
\hline \multicolumn{4}{|c|}{ Vehicle B in charge depleting mode } \\
\hline Hyzem & 3.03 & -1.00 & -0.02 \\
\hline NEDC & 2.74 & -0.71 & -0.07 \\
\hline $\begin{array}{l}\text { US } \\
\text { Combine }\end{array}$ & 2.57 & -0.84 & -0.09 \\
\hline WLTP $3 b$ & 2.82 & -0.96 & -0.14 \\
\hline \multicolumn{4}{|c|}{ Vehicle B in charge sustaining mode } \\
\hline Hyzem & 9.31 & -3.07 & -0.06 \\
\hline NEDC & 8.45 & -2.16 & -0.18 \\
\hline $\begin{array}{l}\text { US } \\
\text { Combine }\end{array}$ & 7.91 & -2.58 & -0.28 \\
\hline WLTP $3 b$ & 8.70 & -2.94 & -0.45 \\
\hline
\end{tabular}


Table 3 Comparing energy reduction values ERVs across powertrain types

\begin{tabular}{|c|c|c|c|c|c|c|}
\hline \multirow[t]{3}{*}{ Vehicle A } & \multicolumn{3}{|c|}{$\operatorname{BEV}(M=1300 \mathrm{~kg})$} & \multicolumn{2}{|c|}{$\operatorname{ICV}(M=1099 \mathrm{~kg})$} & \\
\hline & \multicolumn{6}{|c|}{$A_{F}=2.2 m^{2}, r_{\text {tire }}=0.3 m, f_{R}=0.0085, c_{D}=0.25, P_{\max }=100 \mathrm{~kW}$} \\
\hline & $\eta_{\text {baseline }}$ & $\mathrm{ERV}_{\text {no re }}$ & $E R V_{\text {re }}$ & $\eta_{\text {baseline }}$ & $E R V_{\text {no re }}$ & $E R V_{\text {re }}$ \\
\hline Hyzem & $65.3 \%$ & 1.88 & 2.78 & $26.2 \%$ & 5.39 & 8.824 \\
\hline NEDC & $70.5 \%$ & 1.94 & 2.57 & $21.5 \%$ & 6.43 & 9.936 \\
\hline US Combined & $73.7 \%$ & 1.69 & 2.40 & $22.9 \%$ & 5.57 & 8.766 \\
\hline WLTP $3 b$ & $81.2 \%$ & 1.82 & 2.55 & $22.4 \%$ & 7.17 & 10.801 \\
\hline \multirow[t]{3}{*}{ Vehicle B } & \multicolumn{3}{|c|}{$\operatorname{BEV}(M=1700 \mathrm{~kg})$} & \multicolumn{3}{|c|}{$\operatorname{ICV}(M=1352 \mathrm{~kg})$} \\
\hline & \multicolumn{6}{|c|}{$A_{F}=2.4 \mathrm{~m}^{2}, r_{\text {tire }}=0.3 \mathrm{~m}, f_{R}=0.0085, c_{D}=0.3, P_{\max }=150 \mathrm{KW}$} \\
\hline & $\eta_{\text {baseline }}$ & $\mathrm{ERV}_{\text {no re }}$ & $\mathrm{ERV}_{\mathrm{re}}$ & $\eta_{\text {baseline }}$ & $\mathrm{ERV}_{\text {no re }}$ & $\mathrm{ERV}_{\mathrm{re}}$ \\
\hline Hyzem & $63.0 \%$ & 2.03 & 3.01 & $26.0 \%$ & 5.11 & 9.19 \\
\hline NEDC & $68.5 \%$ & 2.03 & 2.67 & $19.7 \%$ & 5.86 & 11.52 \\
\hline US Combined & $71.6 \%$ & 1.72 & 2.48 & $22.0 \%$ & 5.06 & 9.70 \\
\hline WLTP 3b & $78.6 \%$ & 1.87 & 2.68 & $21.1 \%$ & 6.79 & 11.88 \\
\hline
\end{tabular}

cross-technology analysis that the two powertrain models can be used for.

The BEV Vehicle A in Table 3 is the same as shown in Table 1. It has a $201 \mathrm{~kg}$ battery pack, which yields a $190 \mathrm{~km}$ single-charge range in the UDDS driving cycle. The ICV Vehicle A has a mass of $1099 \mathrm{~kg}$. All other shared vehicle specifications are equal. Due to the lower mass, the ICV has a lower energy demand at the tire patch, $\mathrm{ED}_{\mathrm{T}}$, than the BEV. Due to the much lower powertrain efficiency, the ICV still has a much higher fuel energy demand, $\mathrm{ED}=\mathrm{ED}_{\mathrm{T}} / \eta$ (in $\mathrm{MJ} / 100 \mathrm{~kg} 100 \mathrm{~km}$ ), than the BEV. The powertrain of the BEV Vehicle $\mathrm{A}$ is 2.5 to 3.6 times more efficient than the powertrain of the ICV Vehicle A. As a result, the BEV has much lower ERVs than the ICV. The ratio of energy reduction values, $E R V_{\text {ICV }} / E R V_{B E V}$, reflects and somewhat exceeds the ratio of powertrain efficiencies. Without motor/engine resizing the ratio ranges from 2.9 to 3.9 . With motor/ engine resizing it ranges from 3.2 to 4.2 .

Vehicle B is somewhat larger and heavier, and has thus a more powerful motor/engine. The BEV version has a $347 \mathrm{~kg}$ battery pack, which yields a $250 \mathrm{~km}$ single-charge range in the UDDS driving cycle. Compared to Vehicles A, Vehicles B have slightly reduced powertrain efficiencies, which mostly translates into slightly larger energy reduction values. In general, the analyses of both vehicles, A and B, have fairly similar results. To summarize the two examples, the ratio of powertrain efficiencies, $\eta_{\mathrm{BEV}} / \eta_{\mathrm{ICV}}$, and energy reduction values, $\mathrm{ERV}_{\mathrm{ICV}} / \mathrm{ERV}_{\mathrm{BEV}}$, fall roughly in the range of 3 to 4 . The powertrain efficiencies from the BEV simulations are likely to be underestimates since the simulations did not include a gearbox. Having multiple gears available would enable the motor to operate at higher efficiencies. The effect of this could easily be tested by adding gears to the simulation.

\subsection{Limitations and outlook}

This paper introduces an open-source powertrain model for BEVs and series-PHEVs. Its computational transparency and its use of driving cycles, a net force demand, and motor and generator maps makes it a valuable complement to the existing models and approaches. The LCA community will benefit from having multiple resources available for such an important aspect of environmental vehicles assessments.

The open-source nature of the Excel spreadsheets also allows users to modify and update the model, e.g., by adding driving cycles and motor or generator maps. In principle, it is also possible to add to or modify the computational structure of the model, but this would require more effort. One significant limitation of the presented powertrain model is that it does not currently simulate parallel hybrid powertrain designs. In parallel designs, engine and motor are both directly connected to the axle and can thus both directly supply power. Such a powersplit mode requires a power-split operating logic, which could be implemented in principle, but has been deemed out of scope within the presented research.

The model does have a few features that have not been discussed here but are readily available to model users. One is the use of gears. It would be interesting to examine the extent to which gears increase the efficiency of BEVs/seriesPHEVs. Another is the details of the drive battery design, such as cell specs, arrangement, and charge/discharge behavior.

Making this spreadsheet model available is meant to encourage the LCA community to take a closer look at powertrain physics and modeling.

Acknowledgements We thank the World Auto Steel for partial funding of this research. 
Open Access This article is licensed under a Creative Commons Attribution 4.0 International License, which permits use, sharing, adaptation, distribution and reproduction in any medium or format, as long as you give appropriate credit to the original author(s) and the source, provide a link to the Creative Commons licence, and indicate if changes were made. The images or other third party material in this article are included in the article's Creative Commons licence, unless indicated otherwise in a credit line to the material. If material is not included in the article's Creative Commons licence and your intended use is not permitted by statutory regulation or exceeds the permitted use, you will need to obtain permission directly from the copyright holder. To view a copy of this licence, visit http://creativecommons.org/licenses/by/4.0/.

\section{References}

Amirault J et al. (2009) The electric vehicle battery landscape: opportunities and challenges. Center for Entrepreneurship \& Technology (CET) Technical Brief Number: 2009.9.v.1.1, December 21

Anderson M (2003) Powertrain design and integration lecture, vehicle systems integration course AUTO501, University of Michigan, May 19

A123 Systems (2012) ANR26650, M1-B data sheet, A123 Systems, Waltham, MA

Bedsworth L, Taylor M (2007) Learning from California's zeroemissions vehicle program. California Economic Policy 3(4):1-19. Public Policy Institute of California: San Francisco, CA

Brooker A, Jacob Ward J, Lijuan Wang L (2013) Lightweighting impacts on fuel economy, cost, and component losses. SAE Technical Paper 2013-01-0381

Brooker, A.; Gonder, J.; Wang, L.; Wood, E. et al. (2015) FASTSim: a model to estimate vehicle efficiency, cost and performance. SAE Technical Paper 2015-01-0973. DOI https://doi.org/10.4271/201501-0973

Chana H, Fedewa W, Mahoney J (1977) An analytical study of transmission modifications as related to vehicle performance and economy. SAE Tech Paper 770418. https://doi.org/10.4271/770418

Das S, Graziano D, Upadhyayula VKK, Masanet E, Riddle M, Cresko J (2016) Vehicle lightweighting energy use impacts in U.S. light-duty vehicle fleet. Sustain Mater Technol 8:5-13. https://doi.org/10. 1016/j.susmat.2016.04.001

Erjavec J (2013) Hybrid, electric \& fuel-cell vehicles. Cengage Learning, Boston ISBN-13: 978-0-8400-2395-7

Flamand L, Dalmaz G, Dowson D, Childs THC, Berthier Y, Georges JM, Lubrecht A, Taylor CM (eds) (1998) Tribology for energy conservation, 1st edn. Elsevier, Amsterdam

Genta G, Morello L (2009) The automotive chassis, volume 1components design. Springer, Berlin

Geyer R (2008) Parametric assessment of climate change impacts of automotive material substitution. Environ Sci Technol 42(18): 6973-6979. https://doi.org/10.1021/es800314w

Geyer R (2016) The industrial ecology of the automobile. In: Clift R, Druckman A (eds) Taking stock of industrial ecology. Springer, Berlin, p 331

Geyer R, Malen D (2020) Parsimonious powertrain modeling for environmental vehicle assessments: part 1 - internal combustion vehicles. Int J Life Cycle Assess

Hawkins TR, Singh B, Majeau-Bettez G, Hammer Strømman A (2012) Comparative environmental life cycle assessment of conventional and electric vehicles. J Ind Ecol 17(1):53-64

Heywood JB (1988) Internal combustion engine fundamentals. McGrawHill, NY

Kim H, Wallington TJ (2013a) Life-cycle energy and greenhouse gas emission benefits of lightweighting in automobiles: review and harmonization. Environ Sci Technol 47(12):6089-6097. https://doi. org/10.1021/es3042115
Kim H, Wallington TJ (2013b) Life cycle assessment of vehicle lightweighting: a physics-based model of mass-induced fuel consumption. Environ Sci Technol 47(24):14358-14366. https://doi. org/10.1021/es402954w

Kim H, Wallington TJ (2015) Life cycle assessment of vehicle lightweighting: novel mathematical methods to estimate use-phase fuel consumption. Environ Sci Technol 49(16):10209-10216. https://doi.org/10.1021/acs.est.5b01655

Koffler C, Rohde-Brandenburger K (2010) On the calculation of fuel savings through lightweight design in automotive life cycle assessments. Int J Life Cycle Assess 2010(15):128-135. https://doi.org/ 10.1007/s11367-009-0127-z

Koffler C, Rohde-Brandenburger K (2018) Reply to Kim et al. (2019): Commentary on "correction to: on the calculation of fuel savings through lightweight design in automotive life cycle assessments" by Koffler and Rohde-Brandenburger. Int J Life Cycle Assess 2019: 400-403. https://doi.org/10.1007/s11367-019-01585-y

MacLean HL, Lave LB (2003) Life cycle assessment of automobile/fuel options. Environ Sci Technol 37(23):5445-5452. https://doi.org/10. $1021 / \mathrm{es} 034574 \mathrm{q}$

Mi C, Abul Masrur M, Gao D (2011) Hybrid electric vehicles. Wiley, Hoboken ISBN: 978-0-470-74773-5

Modaresi R, Pauliuk S, Løvik AN, Mu DB (2014) Global carbon benefits of material substitution in passenger cars until 2050 and the impact on the steel and aluminum industries. Environ Sci Technol 48: 10776-10784

Nelson P, Vijayagopal R, Gallagher K, Rousseau A (2013a) Sizing the battery power for PHEVs based on battery efficiency, cost and operational cost savings. World Electr Veh J 6:514-522

Nelson P, Gallagher K, Bloom I, Dees D (2013b) Modeling the performance and cost of lithium-ion batteries for electric vehicles. Second Edition, Chemical sciences and engineering division, Argonne National Laboratory, ANL-12/55, Argonne, IL

Palazzo J, Geyer R (2019) Consequential life cycle assessment of automotive material substitution: replacing steel with aluminum in production of North American vehicles. Environ Impact Assess Rev 75: 47-58. https://doi.org/10.1016/j.eiar.2018.12.001

PDM (n.d.) Regenerative braking deep dive, http://www.pmdcorp.com/ news/articles/html/Regenerative_Braking_Deep_Dive.cfm

Peng H (2006) Lecture notes: energy and environment, AUTO501. University of Michigan, Ann Arbor

PNGV (2001) Battery test manual, U.S. Department of Energy, February

Ross M (1997) Fuel efficiency and the physics of automobiles. Contemp Phys 38(6):381-394. https://doi.org/10.1080/001075197182199

Samaras C, Meisterling K (2008) Life cycle assessment of greenhouse gas emissions from plug-in hybrid vehicles: implications for policy. Environ Sci Technol 42:3170-3176

Serrenho AC, Norman JB, Allwood JM (2017) The impact of reducing car weight on global emissions: the future fleet in Great Britain. Philos Trans R Soc A Math Phys Eng Sci 375:20160364. https:// doi.org/10.1098/rsta.2016.0364

Sullivan JL, Cobas-Flores E (2001) Full vehicle LCAs: a review. SAE Technical Paper 2001-01-3725. DOI https://doi.org/10.4271/200101-3725

UQM (n.d.) SPM286-149-2 Motor/Generator specification sheet, http:// www.uqm.com , 4120 Specialty Pl., Longmont CO 80504

USABC and DOE (1996) Electric vehicle battery test procedures manual, USABC and DOE National Laboratories, January

Waters W (1972) General purpose automotive vehicle performance and fuel economy simulator. SAE Tech Paper 720043. https://oi.org/ $10.4271 / 720043$

Publisher's note Springer Nature remains neutral with regard to jurisdictional claims in published maps and institutional affiliations. 